\title{
Pricing Dynamics of Network Utilities in Developing Countries
}

\author{
OMAR CHISARI \\ Universidad Argentina de la Empresa and CONICET \\ IOANNIS N. KESSIDES * \\ The World Bank
}

\begin{abstract}
This paper examines the pricing of a utility with an underdeveloped network facing a competitive fringe, short-run network adjustment costs, theft of service, and the threat of retaliatory government intervention that is increasing with the price it charges. Under a variety of plausible assumptions (in the context of developing countries) the utility will find its long-run profits enhanced if it exercises pricing restraint in the early stages of network development. These findings provide some useful insights for the design of post-privatization regulatory governance in developing countries where years of price controls have contributed to choking off investment in network expansion.
\end{abstract}

\section{Introduction}

The model presented in this paper is motivated by the observed structural features of developing countries, including their unique socioeconomic characteristics, institutional endowments, weak regulatory mechanisms, and privatization experiences, as well as the coverage ratios and other structural attributes of their public utilities. It is a dynamic model of a utility in a sector with a low coverage ratio, thus facing significant network expansion opportunities but also the prospect of entry or expansion by a competitive fringe. The rate of expansion of the utility's (or equivalently the fringe's) network is assumed to vary continuously with the price set by the utility - the higher the utility's price, the more customers will join the fringe and hence the slower will be the expansion of the utility's network. A portion of the customers that leave the utility's network because of higher prices may engage in service theft - a plausible assumption in the context of many developing countries. The utility maximizes its long-run profits by balancing the impact of its pricing policy on current profits against the impact of such policy on the size of its network. The utility's optimal price path depends upon its cost advantage relative to the fringe, the speed with which existing and potential customers respond to the price differential between the utility and the fringe, the discount rate, the nature of the adjustment costs that it faces with respect to network expansion, and the character of regulation. When the utility has a unit cost advantage over its fringe competitors, it sets

\footnotetext{
* Contact author: The World Bank, 1818 H Street, N.W., Washington, D.C., 20433. E-mail: ikessides@worldbank.org This paper was prepared as part of the Research Program on Industrial Organization Policy for Development at the Development Research Group of the World Bank. Funding from the Bank Netherlands Partnership Program is gratefully acknowledged. We thank an anonymous reviewer, the editors Julian Wright and John Panzar, Daniel Benitez, Eric Groom, Atsushi Iimi, Michael Klein, Abel Mejia, Luis Serven, Michael Toman, and Maria Vagliasindi for very helpful comments.
} 
low tariffs initially in order to develop its network more rapidly and thus reap larger revenues and profits in the future. As the size of the utility's network approaches its asymptotic optimum, it raises its price toward the limit defined by the unit costs of the fringe.

In our model, the utility's pricing behavior is also restrained by the reaction of society. The utility recognizes the threat of government retaliatory intervention by a subjective probability distribution over the initiation date of such intervention. Thus, the utility behaves like a Stackelberg leader when it designs its pricing policy. The effects of an increase in its price are realized as an increase in the hazard rate which will hasten the expected time of government intervention. When the government intervenes by forcing the renegotiation or even termination of the utility's privatization contract, the utility suffers a substantial reduction in its future stream of earnings.

For much of the twentieth century and in most countries, network utilities - electricity, natural gas, railroads, water supply, and telecommunications - were vertically and horizontally integrated state monopolies under ministerial control. Infrastructure's enormous economic importance, a desire to protect the public interest in industries supplying essential services, and concerns about private monopoly power led governments to conclude that control over these services could not be entrusted to the motivations and penalties of free markets. Governments also believed that, given the large investments involved, public resources were required to increase utility coverage. Thus, most of the world chose nationalization over regulation - except the United States, where the network utilities were under private ownership but subject to comprehensive regulatory controls.

Initially, the state-owned, monolithic utility model produced reasonably satisfactory results (Fare et al, 1985). In recent years, however, it has proven increasingly unsuited to changing market and technological conditions in both industrial and developing countries. And it ultimately has led to serious problems for the public interest. In the developing countries, the key problem of the old model was underinvestment in large part caused by underpricing. The state-owned utilities in those countries have proven hopeless at attributing the right cost of capital, particularly in high inflation periods, so that prices fell to levels that could not sustain a rate of investment out of retained profits to meet demand growth. Price controls were imposed in disregard of the performance implications of the pricing rules involved, subjecting the operating entities to considerable financial distress and substantially impairing their ability to maintain and expand service, especially in periurban and rural areas. Years of underfunding led to a sizeable infrastructure deficit in most developing countries where a significant portion of the population was without access to basic utility services (Estache and Fay, 2007).

During the past two decades, nearly all industrial and many developing and transition economies have implemented far-reaching utility reforms. These institutional reforms have entailed combinations of competitive restructuring, privatization, and establishment of regulatory mechanisms in developing countries. One of the primary motivations of these efforts to bring private sector participation into the utilities has been the urgent need for sizeable new investment (Guasch et al, 2003). And while experiences have varied considerably across countries and industries, most utility reforms have improved several aspects of performance. Productivity and cost-effectiveness have risen. Service quality has improved. Investment and service coverage have increased. And services have become more responsive to consumer and business needs and to opportunities for innovation (Gassner et al, 2008). However, despite these gains, coverage ratios in many developing countries are still quite low. For example, in Sub-Saharan Africa, only $26 \%$ of the 
population has access to electricity, $1 \%$ to fixed telephony, $14 \%$ to mobile, $60 \%$ to water, and $34 \%$ to rural transport services. In South Asia, the corresponding coverage ratios are $52 \%$ in electricity, $3 \%$ in fixed telephony, $15 \%$ in mobile, $80 \%$ in rural water, and $57 \%$ in rural transport (World Bank, 2008). Moreover, in most of these countries, old-style centralized price setting is still conducted by ministries with a mandate to establish price controls on a macroeconomic basis (Bruce et al, 1999). And more recently, utilities around the world have been facing an increasingly adverse climate for generating the financing required to maintain and expand their operations.

In view of the continuing significant access gaps and the consequent need for investment flows to expand utility services in developing countries, it would be important to reappraise the role of pricing constraints and other potential regulatory impediments to sustainable investment in these sectors. Broadly speaking, such price controls have impaired the ability of utility operators to finance their future expansion and thus have affected the overall dynamics of their growth. Investors and financial advisors have been increasingly calling for policy initiatives which provide the utility operators sufficient pricing flexibility to adopt to new market realities and enhance their ability to finance their investment needs (Bruce and Macmillan, 2002). Other have argued that especially in developing countries, the removal of such price controls could exacerbate existing affordability problems and significantly disrupt users' ability to absorb tariff rebalancing and other potential post-privatization price adjustments. ${ }^{1}$

Thus an important post-reform issue confronting policy makers and regulatory authorities in developing countries is how much pricing flexibility to accord to their privatized utilities to eliminate service backlogs. In many of these countries, effective demand for infrastructure services at current prices continues to substantially exceed supply, resulting in long waiting lists for service. Under these conditions, the utility's profit maximization is a dynamic optimization problem - to expand capacity at a profitmaximizing rate given short-term adjustment costs and potential diseconomies of scale to capacity expansion (marginal costs of network expansion are likely to increase as the utility reaches rural and low density areas). In formulating its various policies, including those with respect to pricing, the utility has to take into account both the current-profit and future-profit effects of those policy determinations. The two effects are generally competing with each other. For example, a price increase that is favorable to current profit will entail a sacrifice of future profits because it is likely to slow network expansion which in turn would generate future profits for the utility. Alternatively, the utility might choose to price low initially and thus sacrifice current profits for the sake of accelerating the expansion of its network and reaping higher profits in the future. At the optimum, the utility's policy choice must balance the marginal increase (decrease) in current profits induced by its policy choice against the marginal decrease (increase) in future profits that the policy will entail. In the face of significant network expansion opportunities and under a variety of plausible assumptions regarding the nature of technology, costs and demand facing the infrastructure entities, dynamic optimization will lead to low pricing (relative to the short-run profit maximizing monopoly level) in the early stages of network development. Thus, there may be a rationale for granting the utility some pricing flexibility during the early stages of network development.

\footnotetext{
${ }^{1}$ However, these concerns about the potential adverse distributive impacts of pricing flexibility should not be exaggerated. After all, in developing countries with low coverage ratios, nearly all rural and many poor urban residents lack access to basic utility services. Thus, reforms such as eliminating cross-subsidies and moving toward cost-reflective prices, are not generally regressive because they mainly affect higher-income groups.
} 
There are two additional potential arguments for decentralizing pricing decisions to the firm level during the early post-reform years. First, the pursuit of pricing and other regulations to elicit optimal industrial performance in many developing countries is hindered by the lack of proper accounting systems and by the dearth of information on marginal costs, demand elasticities, and other pertinent attributes of demand and cost relationships (Laffont, 2005). Under the traditional command-and-control regulatory model, any prices calculated without such information are apt to be inconsistent with economic efficiency and damaging to economic welfare. The information available to the firms themselves is also highly imperfect in many developing countries. Still, it seems likely that the firms will have better and more up-to-date estimates of cost and demand conditions than the regulators (Baumol and Sidak, 1994).

How can regulators in developing countries acquire a realistic chance of becoming effective in the face of such severe information problems? One promising policy direction would be to decentralize the decisions on pricing and other key variables to the firms that have the necessary information. The role of the regulator would be limited to imposing floors and ceilings on prices (to protect against predation and monopolistic pricing). The price-determining process then would be left to the firm, which would be free to select prices within the floor-ceiling limits. In the face of significant network expansion opportunities the firm's self-interest would motivate it to adopt prices that best serve the public interest. Such a framework could meet the dual policy objectives of giving the utilities an opportunity to obtain adequate revenue to support needed investment (an important issue in many sectors in developing countries) and protecting consumers from monopolistic pricing.

Second, it is widely accepted that an indispensable precondition for the success of utility reforms is the adoption and promotion of pricing policies that provide signals and incentives for efficiency by consumers, suppliers and investors. The realignment of prices with underlying economic costs is surely necessary both for the revenue adequacy of operators and for the public interest. Clearly, pricing policies that lead to fiscal drain, chronic under-investment and inadequate maintenance do not serve the public well in the long run. Moreover, despite their purported focus on social equity, the historic pricing policies of most developing countries have not served the poor well either, since many of them have not had access to basic infrastructural services. Still, aggressive price increases by the privatized utilities have frequently led to violent street riots, skeptical press coverage, populist political backlash, and mounting criticism of international financial institutions that supported and promoted these reforms. ${ }^{2}$ As a result, in several instances the privatization agreements have been renegotiated or even terminated causing substantial financial losses and reductions in the profits of the operating utilities. There are numerous examples of public outcry which led to or forced a retaliatory government reaction to what were perceived to be drastic tariff hikes by the utilities. In the Argentine province of Tucuman, severe price hikes led to popular protests and the termination in 1998 of a 30 year private concession for water provision. Similar price hikes led in 2001 to the cancellation of the Vivendi water concession in Nairobi, Kenya. In the spring of 1993, the specter of electricity price increases launched a wave of mass protests in Guatemala. More

\footnotetext{
${ }^{2}$ This hostility has not been limited to a few radical protesters. Public opinion polls in several developing and transitions economies, especially in Latin America, reveal growing disenchantment with the privatization of utilities. In 2002 nearly 90 percent of Argentines and 80 percent of Chileans polled disapproved of privatization despite demonstrable improvements in the performance of privatized utilities (Andres et al, 2008).
} 
recently, in February 2009, the announced price increases by the natural gas and electricity distribution utilities led to several nationwide protests in Argentina (Crooks, 2009; Dwivedi et al, 2007; Engler, 2002).

It should be noted that the paper does not attempt full-blown normative analysis where a welfare/social surplus objective function is specified and explicit normative results are derived as a benchmark. This is not only due to the analytic complexity of such undertaking. It is also due to the fact that designing effective regulation in developing countries has proven a truly daunting task for several reasons. Some of these are endemic to utility regulation everywhere, while some others are oddly shaped shadows cast by the stubborn complexities of underdevelopment. In the face of scarce technical expertise, severe information problems, lack of well-developed accounting and auditing systems, weak separation of powers, lack of checks and balances, weak legal systems, high incidence of corruption, and low levels of commitment, the US-UK regulation models have proven too challenging for many developing countries. Most of these countries are illsuited to the traditional quasi-judicial, command-and-control techniques of regulation, with their elaborate and complex procedural requirements. More appropriate regulatory mechanisms for most developing countries might indeed be simpler, decentralized, flexible, and less formal. We therefore do not see too much value in modelling the case of a social planner who designs socially optimal regulations, because they are unlikely to be effectively (or even at all) implemented (Kessides, 2004). Instead, we model the behavior of a profit maximizing utility to show that under a variety of realistic assumptions (significant network expansion opportunities and the risk of a popular backlash and punitive government intervention against drastic price increases) it will keep its price low without explicit regulatory control. The results of the paper provide some support to the claims by investors and financial advisors that granting pricing flexibility to utilities in developing countries can provide stimulus to the expansion of infrastructure and the reduction of waiting lists without suffering the full adverse consequences of monopolistic pricing distortions which would normally arise in the context of advanced industrial countries with mature utility networks.

\section{The basic model}

We consider an infrastructure sector that has undergone privatization and where the statutory restrictions on competition have been eliminated. During the early stages of the post-reform process, the incumbent utility is still dominant, although it is facing a competitive fringe. Moreover, the sector's coverage ratio is very low - that is, the utility is facing significant network expansion opportunities. From a public policy perspective, in the face of significant investment requirements rate of return regulation would be appropriate. Unfortunately, most developing countries do not have well-established cost accounting and auditing systems. And since they often lack regulatory expertise, it would be very difficult to effectively implement a rate of return regulatory mechanism. A price cap regime is informationally less demanding. However, it shifts most of the risk to the utility operators and therefore would not be effective in attracting the needed investment.

A common characteristic of developing countries is that a significant portion of their population, especially in periurban and rural areas, is without access to basic services. Thus, their network utilities are characterized by low coverage ratios. We consider an infrastructure sector that has not as yet achieved full coverage. A single utility firm 
dominates the sector serving $N$ out of $M$ potential customers. The remaining $M-N$ consumers are either being served by alternative service providers (fringe), have no access at all, or a certain portion $\rho$ of them may actually steal the service from the dominant utility through illegal connections. The services offered by the dominant utility and the fringe are assumed to be interchangeable in terms of their utility to the consumers. ${ }^{3}$

The service arrangements of the customers not connected to the utility's formal network vary by sector and country. In Yemen's electricity sector, for example, small generators supply rural towns and villages not served by the public utility. Operations range from individual households generating power for themselves and a few neighbors to units supplying up to 200 households (Ehrhardt and Burdon, 1999). Electricity theft through illegal connections is a serious problem in many developing countries, especially in the inner city communities and urban areas. Electricity theft accounted for over onequarter of total production in 1992 when privatization reforms were initiated in Argentina (Haselip, 2004). In Jamaica, in excess of 30,000 illegal connections were removed each month during 2003, allowing for a monthly reduction of 4.5 MWh of electricity production (Jamaica Public Service Company, 2004). A 1989 study of the water supply in the Nigerian town of Onitsa found that water vendors delivered more water than the public water utility and that revenues for vended water exceeded revenues for water supplied by the public utility by a factor of more than 10 (Whittington et al, 1991). These results indicated significant opportunities for expansion by the public utility.

Let $P$ denote the average revenue generated by the utility from each customer unit and $\xi(N)$ represent the minimum unit cost of the fringe service providers. We assume that the dynamics of network expansion are characterized by the differential equation

$$
\dot{N}=\gamma[\xi(N)-P]
$$

where $\dot{N}$ is the rate of the dominant utility's customer base expansion and the coefficient $\gamma$ reflects the speed at which existing and potential customers respond to the price differential between the dominant utility and the fringe. Equation (1) implies that the rate at which customers join (or leave) the dominant utility's network varies continuously with its current price- $\xi(N)$ is the limit price, that is, that price level at which the dominant utility experiences zero network expansion. Charging less than the unit cost of the fringe $\xi(N)$ represents an investment in creating a larger network of customers which could yield dividends in terms of larger future revenues and profits. Pricing above the unit cost of the fringe, on the other hand, causes exit of customers from the utility's network and the loss of profitable network expansion opportunities. ${ }^{4}$

\footnotetext{
${ }^{3}$ This assumption of service homogeneity is likely to be violated in many real-world circumstances. Clearly, the characteristics of the services offered by the dominant utility can differ from those offered by the fringe on several dimensions of quality. Still, in the context of many developing countries where large segments of the population remain without access to basic services, costs rather than product differentiation are likely to be the main driving force. This paper, therefore, focuses more on the nature of production technology and costs facing the fringe rather than the properties of the demand function.

${ }^{4}$ The dynamics of network expansion described by (1) are similar to the entry equation used by Gaskins (1971) and the vast literature that followed. The intertemporal pricing issues faced by regulated monopolists have been analyzed by, among others, Faulhaber and Boyd (1989).
} 
Let $C$ denote the utility's total cost of serving its network of $N$ customers. We allow for the possibility that a portion $\rho$ of the $M-N$ unserved customers will illegally connect to the utility's network. ${ }^{5}$ We further assume that

$$
C=F+c(N, \rho(M-N))
$$

where $F \geq 0$ represents the utility's fixed network costs and $c$, its variable cost function, is twice differentiable with $c_{N}>0$ and $c_{M-N} \geq 0$.

\subsection{Intertemporal profit maximization}

The dominant utility's long-run profit-maximization problem can be solved using the techniques of optimal control theory. The firm chooses the price $P(t)$ - control variable to maximize its profit performance functional subject to some dynamic constraints. These constraints describe the evolution of the structure of the utility's network, as represented by the state variable $N(t)$, over time. Thus, the utility's long-run profit-maximization problem is given by

$$
\max _{P(t)} \Pi(0)=\int_{0}^{\infty} e^{-r t}\left[P N-C(N)-\phi \dot{N}^{2}\right] d t
$$

subject to

(a) $\dot{N}=\gamma[\xi(N)-P]$,

(b) $N(0)=N_{0}$, given,

(c) $\lim _{t \rightarrow \infty}\left[N(t) e^{-r t}\right]=0$.

where $\Pi(0)$ is the value of the utility's profit function at time $0, r$ is the discount rate which is assumed to be constant over time, and the term $\phi \dot{N}^{2}$ represents the adjustment costs the utility must incur in changing the size of its network (Brock and Dechert, 1985; and Hamermesh and Pfann, 1996).

The expansion constraint in (3a) is the transition equation or equation of motion, and shows how the choice of the control variable, $P(t)$, translates into a pattern of movement for the state variable, $N(t)$. Equation (3b) simply states that the state variable $N(t)$, representing the size of the utility's network, starts at time 0 with a given value $N_{0}$. And $(3 \mathrm{c})$ is the well-known transversality condition.

The present value Hamiltonian of this problem is given by:

$$
H(N, P, t, \lambda)=e^{-r t} \Pi(P, N)+\lambda(t) \gamma[\xi(N)-P]
$$

where $\Pi(P, N)=P N-C(N)-\phi \gamma^{2}[\xi(N)-P]^{2}$ and $\lambda(t)$, is the Lagrange multiplier associated with the constraint in (1). The Lagrange multiplier can be interpreted as a shadow price $-\lambda(t)$ is the imputed value to the utility of an extra customer at time $t$. The economic interpretation of the Hamiltonian in this problem is quite straightforward. The

\footnotetext{
${ }^{5}$ It should be noted that $\rho$ can be implicitly determined by the institutional environment and the state of the economy. Macroeconomic shocks can be associated with increased failure to collect bills and reduce theft. As the Argentine crisis of 2001 indicates, under those circumstances the relaxation of collection standards can be tolerated by the utilities themselves.
} 
first component of the right hand side of (4) is simply the profit function at time $t$ which is dependent on the utility's pricing decision and the size of its network at that time. The second component of (4) represents the rate of change of network size which is converted to a monetary value when it is multiplied by the shadow price $\lambda$. At every instant in time, the utility chooses a price $P(t)$ and has a network with $N$ customers. These two variables affect the utility's objective function (profit) through two channels. First, the direct impact of $P(t)$ and $N$ on the utility's profit function is captured by the first term in (4). Second, the price $P(t)$ chosen by the utility affects the change in the size of its network in accordance to the transition equation for $\dot{N}$ in (1). The value of this change is captured by the second term in (4). Thus for a given value of the shadow price $\lambda$, the Hamiltonian captures the total impact on the utility's profit function from the choice of $P(t)$.

In terms of the present value Hamiltonian, the first-order necessary conditions for the utility's intertemporal maximization problem are given by:

$$
\begin{gathered}
H_{P}=e^{-r t}\left\{N+2 \phi \gamma^{2}[\xi(N)-P]\right\}-\lambda \gamma=0 \\
H_{N}=e^{-r t}\left\{P-C^{\prime}(N)-2 \phi \gamma^{2}[\xi(N)-P] \xi^{\prime}(N)\right\}+\lambda \gamma \xi^{\prime}(N)=-\dot{\lambda}
\end{gathered}
$$

These first-order conditions are necessary conditions implied by Pontryagin's Maximum Principle (Pontryagin et al, 1962). And they are sufficient under standard assumptions (see Lemma 1 in the Appendix).

The Hamiltonian and the maximum principle that requires its maximization with respect to $P$ can obtain a more intuitively appealing economic meaning if we define the current value Hamiltonian

$$
H^{c}=\Pi(P, N)+\lambda_{c}(t) \gamma[\xi(N)-P]
$$

Where $\lambda_{c}$ is the current value Lagrange multiplier. At the optimum, we obtain from the first-order conditions for maximization of $H^{c}$

$$
\frac{\partial \Pi}{\partial P}-\frac{\gamma}{r-\gamma \xi^{\prime}(N)} \frac{\partial \Pi}{\partial N}=0 .
$$

The first term in (8) measures the marginal increase in the current profit of the utility that is induced by an increase in its price. The second term represents the marginal decrease in future profits that such a price increase will induce via the change in the size of the utility's network - an increase in the utility's price reduces the price differential between the utility and the fringe, leading to a loss of customers to the fringe and a slower expansion in the utility's network. This effect will be larger the higher the speed $\gamma$ with which existing and potential customers respond to the price differential between the utility and the fringe. If the utility is myopic and discounts future profits very heavily ( $r$ is large), then it will not weigh very much in its pricing decision the impact of such a decision on the future size of its network. The utility will increase its price as long as the marginal gain in current profit made possible by such an increase is greater than the marginal decrease in future profit that its pricing decision will induce via its effect on the size of its network. The utility's optimal choice $P^{*}$ must balance these two effects. 


\subsection{The utility's optimal size and pricing path}

Explicit solutions for $N, P$, and $\lambda$ can be found by specifying $C(N)$ and $\xi(N)$. In general, it costs more to provide utility services to rural than to urban communities. The higher rural investment costs - measured as capital infrastructure costs per unit of service (for example, kilowatt hour in the electricity sector) consumed - largely reflect the lower density of rural connections. In the electricity sector, for example, these costs depend on the community's distance from the existing medium voltage grid, and on the community's size and potential demand pattern. Investment costs per unit of demand are higher in rural areas because the bulk of demand in rural areas is for lighting during the early evening - the ratio of average demand (which determines financial and economic benefits) to peak demand (which determines investment cost) is much lower in rural systems than in urban, where there is considerable daytime electricity use. Many, if not most, developing countries are characterized by low coverage ratios and relatively underdeveloped networks with infrastructure services mainly being offered in the urban areas. In these countries, it can be reasonably assumed that the marginal costs of network expansion are increasing with the size of the network. Thus, we adopt a functional form for the dominant utility's cost function $C(N)$ that is quadratic in the size of the network $N$

$$
C(N)=F+a N+c[\rho M+(1-\rho) N]^{2}
$$

where $a>0$ and $c>0$.

To capture some of the characteristics of the technology of provision of infrastructure services in developing countries, we assume that the production function of the fringe exhibits increasing returns. This can be captured by positing that the minimum unit cost of the fringe service providers, $\xi(N)$, is increasing with $N$. Moreover, as the size $N$ of the formal network increases, the pool of the unserved customers $M-N$ becomes more costly to serve (assuming that the dominant utility expands service to low-cost customers first). Thus, we set

$$
\xi(N)=\xi_{0}+\xi_{1} N
$$

where $\xi_{1}>0$.

It should be noted that there are conceptual differences with other treatments in the literature, because we seek to capture the stylized facts for developing countries. We differ here from Gaskins (1971) where the fringe is assumed to have constant average and marginal cost. Where the fringe represents a small company distributing water with a truck to periurban customers, it is reasonable to assume that because of the presence of fixed costs (for example, the cost of capital of the truck) unit costs will increase as more customers migrate to the network of the dominant water utility - that is, the units costs of the fringe will increase with $N$. The same would apply to a small distributed electricity company with a diesel generator offering services to customers not connected to the grid. Thus, an increase in the size of the formal network confers advantages to the dominant utility not because of the presence of positive demand externalities [for example, Arthur (1989)] but rather because of the changes in the cost function of the fringe (which has to distribute its fixed costs over a smaller customer base).

Differentiating (5) with respect to $t$ and substituting for $\lambda$ and $\dot{\lambda}$ into (6) yields a second-order differential equation in $N$ (Euler equation) 


$$
\ddot{N}-r \dot{N}-\frac{r+2 \gamma c(1-\rho)^{2}-2 \gamma \xi_{1}}{2 \phi \gamma} N=-\gamma \frac{\xi_{0}-a-2 c \rho(1-\rho) M}{2 \phi \gamma} .
$$

Given the requirement that $N(t)$ be bounded as $t \rightarrow \infty$, and the initial condition $N(0)=$ $N_{0}$ as prescribed by (3b), the solution is given by

$$
N(t)=\left(N_{0}-N^{*}\right) e^{-r\left(\frac{\varsigma-1}{2}\right) t}+N^{*}
$$

where $\zeta=\left[1+2 \frac{r+2 \gamma c(1-\rho)^{2}-2 \gamma \xi_{1}}{\phi \gamma r^{2}}\right]^{\frac{1}{2}}$, and

$$
N^{*}=\gamma \frac{\xi_{0}-a-2 c \rho(1-\rho) M}{r+2 \gamma c(1-\rho)^{2}-2 \gamma \xi_{1}}=0
$$

is the steady-state size of the network. We assume that $N^{*}>0$. It should be noted that according to Lemma 1 (in the Appendix), the Mangasarian sufficiency conditions are met if $2 \phi \gamma^{2}\left[C^{\prime \prime}(N)-2 \xi^{\prime}(N)\right]-1>0 \Rightarrow \xi_{1}<c(1-\rho)^{2}-\frac{1}{4 \phi \gamma^{2}}$ which would also imply that $\xi_{1}<c(1-\rho)^{2}+\frac{r}{2 \gamma}$ since $\phi, r$ and $\gamma$ are positive. This would simply imply that $\mathrm{r}+2 \gamma \mathrm{c}(1-\rho)^{2}-2 \gamma \xi_{1}>0$ and thus $\varsigma>1$.

The optimal size of the utility's network is a function of its cost characteristics and those of the fringe, the nature of its competitive interaction with the fringe, the extent to which the utility can exclude customers for non-payment, and the discount rate. Simple comparative static analysis indicates that the optimal size of the utility's network will be:

- Bigger the larger is $\xi_{0}$, the initial unit cost (price) of the fringe.

- Smaller the larger is $a$, its initial marginal cost.

- Bigger the more rapidly the unit costs of the fringe increase as the network absorbs more customers, i.e. the larger $\xi_{1}$ is.

- Smaller the higher is $c$, the utility's marginal cost.

- Smaller the higher is the utility's discount rate $r$.

Equations (1) and (12) imply that the utility's optimal price path is given by

$$
P(t)=\xi_{0}+\xi_{1} N^{*}+\left(N_{0}-N^{*}\right)\left(\xi_{1}+\frac{r}{\gamma} \frac{\varsigma-1}{2}\right) e^{-r\left(\frac{\varsigma-1}{2}\right) t}
$$

with a steady-state price level

$$
P^{*}=\xi_{0}+\xi_{1} \gamma \frac{\xi_{0}-a-2 \gamma c \rho(1-\rho) M}{r+2 \gamma c(1-\rho)^{2}-2 \gamma \xi_{1}} .
$$


It is easy to show that the steady state is a saddle point equilibrium (See Lemma 2 in the Appendix). The utility's terminal price is an increasing function of $\xi_{0}$ and $\xi_{1}$. Thus, it sets a higher price as the unit and marginal costs of the fringe increase.

The initial size $N_{0}$ of the utility might reflect a variety of country-specific characteristics and economic policies (for example, the country's macroeconomic condition, the socioeconomic characteristics of its population, policies related to the structure of ownership and universal access). It can also be the unintended consequence of a host of misguided public policies (for example, failure to prescribe cost-reflective tariffs, statutory restrictions on competition, governmental restrictions on investment) towards the sector. In many developing countries, especially during the pre-reform era, coverage ratios were very low. Large segments of the population remained without access to basic infrastructural services despite willingness to pay for such services. If the initial size $N_{0}$ of the utility's network is small, then from (12)

and

$$
\dot{N}(0)=-r\left(\frac{\varsigma-1}{2}\right)\left(N_{0}-N^{*}\right)>0
$$

$$
P_{0}=P(0)=\xi_{0}+\xi_{1} N_{0}+\left(N_{0}-N^{*}\right) \frac{r}{\gamma} \frac{\varsigma-1}{2}<\xi_{0}+\xi_{1} N_{0}
$$

Thus, the utility's initial price $P_{0}$ is lower than the limit price permitted by the initial unit cost $\xi_{0}+\xi_{1} N_{0}$ of the fringe - the utility prices initially low (below the limit price afforded by the presence of the fringe) in order to expand its network. The amount by which the utility sets its initial price below the limit price is proportional to $N_{0}-N^{*}$ (that is, the difference between its initial and long-run optimal size) with a proportionality constant $\frac{\varsigma^{-1}}{2}$. Given that we defined above $\zeta=\left[1+2 \frac{r+2 \gamma c(1-\rho)^{2}-2 \gamma \xi_{1}}{\phi \gamma r^{2}}\right]^{\frac{1}{2}}$, it is easy to show that the amount by which the utility prices initially below the limit price:

- Increases with $\left(\xi_{0}-a\right)$ - when the dominant utility has a cost advantage over its fringe rivals, it maximizes long-run profits by setting its initial price below the limit price by an amount that is proportional to that cost advantage.

- Decreases with the discount rate $r$ - if the utility discounts future revenues and profits very heavily then the strategy of charging less than the unit cost of the fringe in order to create a larger network of customers and reap the benefit of higher future revenues and profits is clearly less appealing (the proof that $\partial P_{0} / \partial r>0$ is available from the authors).

- Decreases with $\gamma$, the speed with which existing and potential customers respond to the price differential between the dominant utility and the fringe - clearly the more responsive customers are to the price differential the smaller will be the amount by which the utility will need to underprice in order to attract a given number of customers to its network.

- Decreases with $\phi$, the rate at which the utility's adjustment costs increase with the speed with which it expands its network - the utility will have less of an incentive to price aggressively below the fringe in order to rapidly expand its network if the adjustment costs that it incurs rise rapidly with the speed of expansion. 
Through simple differentiation we obtain from (14)

$$
\dot{P}(t)=-\gamma \frac{\varsigma-1}{2}\left(N_{0}-N^{*}\right)\left(\xi_{1}+\frac{\varsigma-1}{2}\right) e^{r \frac{\varsigma-1}{2} t}
$$

If $N_{0}$ is small, then $\dot{P}(t)>0$, that is, the utility follows a path of increasing tariffs.

These results could have significant implications for the design of regulatory policy in developing countries where the utility networks are underdeveloped and only a small portion of the population has access to basic utility services. To the extent that the utility's intertemporal profit-maximization plan calls for a low initial price (relative to the short-run profit maximizing monopoly level), it might not be necessary to subject it to a detailed regulatory scrutiny, at least with respect to pricing. This is comforting because during the early stages of the reform process regulatory agencies in most developing countries lack the requisite technical and economic expertise for effectively monitoring industry performance, analyzing cost data, dealing with information asymmetries, and analyzing the pricing and other elements of behavior of regulated utilities. During the same period, the utility's need for investment flows to maintain and expand its network is likely to be most acute. Therefore, under those circumstances it might be appropriate to accord the utility pricing freedom to develop its network and expand service.

\section{Network pricing and expansion under threat of government punitive intervention}

Public utility services are often regarded as "essential" both to the public and to the effective functioning of the economy. Some of these services also tend to be extremely price and income inelastic. Cost-based utility prices for many households can represent a substantial proportion of their budgets. Price changes can therefore have a considerable impact on the level and distribution of real incomes. Raising the price of basic utility services appears like a lump-sum tax bearing heavily on the poor, elderly, and those with large families (Newbery, 1999). And cultural attitudes toward paying the full cost of utility services change fairly slowly. Utility services are also essential intermediate inputs for other sectors of the economy, and their service levels and prices can have major effects on industrial costs and international competitiveness. Moreover, the presence of only a few utility operators in each locality raises immediate concerns about concentrated and exploitative market power, excessive prices and profits, and restricted freedom of choice. These characteristics create significant opportunities for political mobilization, consumer and special-interest-group activism, and populist manipulation. Not surprisingly, utility price increases generate considerable public opposition and frequently encounter strong political obstacles. Indeed, the movement towards cost-reflective tariffs has been, at least partially, responsible for the growing protests against utility reforms in Latin America and other parts of the world (Andres et al, 2008).

Because a large portion of the utility costs are fixed and sunk, once the investment is made the utility will, in general, continue operating as long as operating revenues exceed operating costs. This motivates governments to behave opportunistically when dealing with the privatized utilities. For example, after the investment is made, the government can lower the regulated prices the utilities charge for their services, impose special taxes, disallow some of the costs, restrict procurement and employment practices, require special 
investments, and restrict the composition and movement of capital. Indeed, most of government-led utility concession renegotiations have been opportunistic, with politicians during or immediately after election campaigns altering the terms and conditions of concessions and other privatization agreements to please their constituents (Guasch and Straub, 2006).

An effective regulatory regime that is characterized by substantial independence, and is subject to such procedural requirements as affording all competent interested parties an opportunity to be heard on major issues of policy, could constitute a barrier against opportunistic behavior by governments. Unfortunately, one of the most serious deficiencies of the regulatory process in developing countries has been the lack of organizational and financial independence of regulation from the politicized arms of government. Indeed, many government entities, such as sectoral ministries, have resisted giving up their regulatory functions, especially those related to pricing. In the face of political agendas that are endemically discretionary and subject to change and reinterpretation, there can be no credible commitment to limit the discretionary powers of the government's regulatory apparatus. Thus, the privatized utilities in developing countries are frequently confronted with policy regimes that pose significant risks of political expropriation - government intervention which can substantially reduce their profits.

If private utilities are vulnerable to administrative intervention, they can be expected to invest less than the socially optimum amount and to make disproportionately low investments in activities with large sunk costs, because once sunk investments are made the balance of bargaining advantage generally shifts from the private investors to the government. Understandably, the owners of private capital will be unwilling to undertake the sunk investments needed to supply utility services when they face the prospect of political expropriation. Thus, the threat of opportunistic behavior by government clearly has negative welfare consequences. On the other hand, the prospect of punitive government action is likely to restrain the utility's pricing behavior. In the face of endogenous government intervention threat, the utility will constrain its pricing behavior and forgo short-term profits to stave off the threatened intervention which could reduce substantially its long-term profits and market value.

\subsection{Pricing under endogenous government intervention threat}

In this section, we analyze the impact of the threat of government retaliatory/opportunistic action on the utility's behavior. ${ }^{6}$ Our underlying assumption is that there is a positive relationship between the price charged by the utility and the probability of retaliatory government intervention. Let $\Psi(t)$ the utility's assessment of the probability of government intervention at time $t$, with $\Psi(0)=0$. The conditional probability density of intervention at time $t$, given its non-occurrence prior to $t$, is $\dot{\Psi}(t) /[1-\Psi(t)]$. We assume that this conditional probability density of intervention is an increasing convex function of the utility's price $P(t)$ :

$$
\frac{\dot{\Psi}(t)}{1-\Psi(t)}=h(P(t))
$$

\footnotetext{
${ }^{6}$ The impact of regulatory threat on firm behavior has received considerable attention in the literature. These contributions include Klevorick (1973), Bawa and Sibley (1980), Logan et al (1989), Glazer and McMillan (1992), Acutt and Elliott (2001), Brunekreeft (2004), Blum et al (2006).
} 
where $h(0)=0, h^{\prime}(P) \geq 0, h^{\prime \prime}(P) \geq 0$ (Kamien and Schwartz, 1991).

The utility's long-run profit-maximization problem is given by

$$
\max _{P(t)} \Pi(0)=\int_{0}^{\infty} e^{-r t}\{\Pi(P, N)[1-\Psi(t)]+\bar{\Pi} \Psi(t)\} d t
$$

where $\Pi(P, N)=P N-C(N)-\phi \dot{N}^{2}$

subject to
(a) $\dot{N}=\gamma[\xi(N)-P]$
(b) $\dot{\Psi}(t)=[1-\Psi(t)] h(P)$,
(c) $N(0)=N_{0}$,
(d) $\lim _{t \rightarrow \infty}\left[N(t) e^{-r t}\right]=0$.

Thus, $P$ is the control variable and $N$ and $\Psi$ are the state variables. The first component of the integrand is the utility's expected profit $\Pi$ at $t$ if there is no government intervention by $t$, while the second component $\bar{\Pi}$ is the firm's reduced profit in the event it is subjected to a retaliatory government action. Since in many developing countries there is a relative lack of due process, $\bar{\Pi}$ could be substantially smaller than $\Pi$.

The current value Hamiltonian is

$$
\begin{gathered}
H^{c}=\Pi(P, N)[1-\Psi(t)]+\bar{\Pi} \Psi(t)+\lambda_{c}(t) \gamma[\xi(N)-P] \\
\left.+\mu_{c}(t) h(P)\right)[1-\Psi(t)]
\end{gathered}
$$

where the costate variables $\lambda_{c}(t)$ and $\mu_{c}(t)$ are the current shadow prices of an extra customer and the probability of regulatory intervention. The sum of the first two terms in (21) represents the current-profit effect of the utility's pricing policy: it realizes a profit $\Pi$ if there is no government intervention by $t$ (probability $1-\Psi(t)$ ) and a profit $\bar{\Pi}$ if there is government intervention by $t$ (probability $\Psi(t)$ ). The third and fourth components of the Hamiltonian can be viewed as the future-profit effects of $P$ : the terms $\lambda_{c}(t) \gamma[\xi(N)-P]$ and $\mu_{c}(t) h(P)[1-\Psi(t)]$ represent the rate of change in the value of the utility's network and the cost of potential government intervention caused by the utility's pricing decision $P$.

The maximum-principle conditions are

$$
\begin{gathered}
\frac{\partial \Pi}{\partial P}\left[1-\Psi(t]-\lambda_{c}(t) \gamma+\mu_{c}(t) h^{\prime}(P)\right)[1-\Psi(t)]=0 \\
\frac{\partial \Pi}{\partial N}[1-\Psi(t)]-\lambda_{c}(t)\left[r-\gamma \xi^{\prime}(N)\right]=-\lambda_{c}^{\prime}(t) \\
-(\Pi-\bar{\Pi})-\mu_{c}(t)[r+h(P)]=\mu_{c}{ }^{\prime}(t) .
\end{gathered}
$$

It can be shown that at the optimum $\frac{\lambda_{c}(t)}{1-\Psi(t)}$ and $\mu_{c}$ are constant. Differentiating (22) with respect to time and substituting for $\lambda_{c}^{\prime}(t)$ and $\mu_{c}{ }^{\prime}(t)$ from (23) and (24) and for $\lambda_{c}(t)$ from (22) yields for the steady state (where $\dot{P}=0$ and $\dot{N}=0$ ) 


$$
\left(\frac{\lambda_{c}(t)}{1-\Psi(t)}\right) \gamma^{2} \xi^{\prime}(N)=\frac{\partial \Pi}{\partial P}[r+h(P)]-\gamma \frac{\partial \Pi}{\partial N}-(\Pi-\bar{\Pi}) h^{\prime}(P)=0 .
$$

Thus, in the steady state $\frac{\lambda_{c}(t)}{1-\Psi(t)}$ is stationary. Equation (22) then implies that $\mu_{c}(t)$ is also stationary. From (24) we obtain for the optimum value of $\mu_{c}$

$$
\mu_{c}^{*}=\frac{-(\Pi-\bar{\Pi})}{r+h(P)}
$$

An increase in the state variable $\Psi$ raises the probability of government intervention and thus reduces the optimal value at a rate proportional to the difference in profits without and with government intervention.

In the steady state $\frac{\lambda_{c}(t)}{1-\Psi(t)}=\delta$ or equivalently $\lambda_{c}(t)=\delta[1-\Psi(t)]$, where $\delta$ is a constant. This implies that $\lambda_{c}{ }^{\prime}(t)=-\lambda_{c}(t) h(P)$. Substituting for $\lambda_{c}^{\prime}(t)$ into (23) yields $\lambda_{c}(t)=$ $\frac{1}{r+h(P)-\gamma \xi^{\prime}(N)} \frac{\partial \Pi}{\partial N}[1-\Psi(t)]$. Finally, by substituting for $\lambda_{c}(t)$ and $\mu_{c}^{*}$ into (22) we obtain at the optimum

$$
\frac{\partial \Pi}{\partial P}-\frac{\gamma}{r+h(P)-\gamma \xi^{\prime}(N)} \frac{\partial \Pi}{\partial N}-\frac{h^{\prime}(P)}{r+h(P)}(\Pi-\bar{\Pi})=0
$$

As in (8), the first term of (27) measures the marginal increase in the current profit of the utility that is induced by an increase in its price, while the second term represents the marginal decrease in future profits that such a price increase will induce via the change in the size of the utility's network. The third term measures the marginal decrease in future profits that a price increase will induce via its impact on the probability of government intervention. The utility's optimal pricing policy must balance these competing effects. An increase in the utility's price increases the conditional probability of government intervention at any moment which would forever reduce the utility's profit to $\bar{\Pi}$. This effect is stronger the more sensitive is the probability of government intervention to the utility's pricing behavior (that is, the larger $h^{\prime}(P)$ is) and the more severe is the punishment imposed by government retaliatory action, that is, the bigger is the set-back in profits $\Pi$ $\bar{\Pi}$. If the utility is myopic and discounts future profits very heavily ( $r$ is large), then it will not weigh very much in its pricing decision the impact of such a decision on the rate of network expansion or on the probability of future government intervention and hence future profits. In that case it will charge a higher price today.

It should be noted that the hazard rate $h(P)$ enters in (27) in two different ways. On the one hand, it augments the utility's discount rate in the second term of (27). Higher values of $h(P)$ imply a higher conditional probability density of damaging government intervention, which (like a higher discount rate) will cause the utility to behave myopically and charge a higher price today. On the other hand, it causes the utility to exercise pricing restraint through $h^{\prime}(P)$ in the third term of (27). So, it is not only the level of the hazard rate that counts, but also its marginal change reflecting the sensitivity of social response to increases in the utility's price. Clearly, in countries where there have been strong public 
protests against price increases, the utility will exercise greater pricing restraint. If the probability of government intervention is constant (that is, invariant with respect to the utility's behavior), then $h^{\prime}(P)=0$ and the third term in (27) becomes zero. Thus, the mere existence of a fixed probability of government intervention does not necessarily affect the utility's behavior (Brunekreeft, 2004). Though an explicit solution is difficult, it is easy to see from (27) that the constant probability of intervention simply augments $r$, the utility's discount rate. Thus $h$ will have the same impact on the utility's optimal price and size that the discount $r$ has.

\subsection{The role of the discount rate}

Equations (8) and (27) illustrate the extent to which the discount rate influences the utility's choice of pricing policy which in turn has important feedback effects on the size of its network and on market structure. The basic idea of the model presented is that the utility maximizes its long-run profitability by adopting a pricing policy which at every instant balances any marginal increase on current profits against the sacrifice of future profits that such a policy might entail via its impact on the rate of the utility's network expansion and the threat of government intervention. The utility's rate of time preference naturally affects the relative weights that it attaches to its current and future profits and hence the time path of prices which maximize the discounted present value of its profits. If the utility employs a very high discount rate it will then exercise less restraint in holding price below the fringe firm's unit cost or the short-run profit maximizing level - the value of future profits that such a restraint will generate via its impact on the rate of the utility's network expansion decreases as the discount rate increases.

Regulation that provides a credible commitment to safeguarding the interest of both investors and customers - particularly when economic shocks create political pressure to shift the balance of power among competing interest groups - is an indispensable precondition for rational long-term planning on the part of the utilities. Unfortunately, because of their long history of arbitrary administrative intervention, governments in many developing countries lack the capacity to credibly commit against political expropriation of private value. Utilities in those countries feel especially vulnerable to unilateral changes in policy or regulatory directives that tend to diminish investor value. The fact that regulatory policy frequently lacks independence, coherence, stability and credibility will drive up the cost of capital for utilities operating in this regulatory environment with a consequent increase in the associated discount rate. This tendency is reinforced by the uncertainty frequently underlying the macroeconomic environment in developing countries.

The initial conditions in developing countries may generate conflicting incentives on the part of their utilities with respect to pricing policy. The fact that these utilities are operating underdeveloped networks with significant expansion opportunities may provide them with powerful incentives to exercise restraint and price below the short-run profit maximizing level during the early stages of network development. The high discount rates that such utilities generally employ in the face of substantial policy uncertainty, on the other hand, will cause them to assign greater weight to current profits and consequently to set their price close to the limit defined by the fringe firms' unit costs. Therefore, if network expansion is a key goal of public policy in developing countries it is imperative that their governments undertake steps to reduce policy risk. 


\section{$4 \quad$ Concluding comments}

We have presented in this paper an analytically tractable intertemporal framework for analyzing the dynamic pricing of a utility with an underdeveloped network facing a competitive fringe, short-run network adjustment costs, theft of service, and the threat of a punitive government intervention that is increasing with the price it charges. This simple dynamic optimization model takes explicitly into account the structural features of developing countries, and as such it yields a number of relevant policy insights.

Our model has been motivated by the observed substantial access gaps that have stubbornly persisted in many developing countries following the privatization and market liberalization reforms in their utility sectors. Some have attributed these continued access gaps to regulatory impediments to sustainable investment that have been reinforced by pricing controls more appropriate for monopolistic markets and not consistent with competitive developments in these sectors. In fact, financial advisors and other industry observers have been calling for the revaluation of a number of aspects of traditional regulatory approaches in the privatized utilities of developing countries that are facing serious challenges in generating the financing required to maintain and expand their utility networks. Knowledgeable observers have also called for granting the operating utilities greater pricing flexibility to address service backlogs and to adopt to new market realities. We are attempting to ascertain whether there is any analytic merit to these proposals.

Our model shows that under a variety of assumptions that are realistic in the context of developing countries (low coverage ratios and thus significant opportunities for network expansion, and political backlash against drastic price increases followed by government retaliatory intervention), the utility will find its long-run profits enhanced if it exercises pricing restraint in the early stages of network development. During the early stages of the reform process, most developing countries also lack the requisite technical and economic expertise to effectively implement a regulatory regime with heavy informational and analytical requirements. Under those conditions, and especially in view of the remaining significant gaps in utility coverage, the public could be better off if the utility were accorded substantial flexibility in setting prices to address existing service backlogs.

The paper's intertemporal framework also highlights the critical importance of a stable, credible, and predictable policy environment for the utilities to expand their networks. If governments are able and willing to impose appropriate limits on the discretionary exercise of their regulatory powers, utilities will feel less vulnerable to unilateral changes in the policy regime that could substantially undermine their profits. Under those circumstances, utilities will tend to employ a low discount rate which effectively will cause them to set low initial prices so as to accelerate the expansion of their networks and reap higher future revenues and profits.

\section{$5 \quad$ References}

Acutt, M. and C. Elliott (2001) "Threat-based Regulation and Endogenously Determined Punishments," Working Paper 2001/007, Lancaster University Management School.

Andres, L., J. Guasch, T. Haven and V. Foster (2008) The Impact of Private Participation in Infrastructure. PPIAF, World Bank: Washington, D.C. 
Arthur, W. (1989) "Competing Technologies, Increasing Returns, and Lock-in by Historical Events,” Economic Journal, 99: 116-131.

Baumol, W. and J. Sidak (1994) Toward Competition in Local Telephony. MIT Press: Cambridge, Massachusetts.

Bawa, V. and D. Sibley (1980) "Dynamic Behavior of a Firm Subject to Stochastic Regulatory Review," International Economic Review, 21: 627-642.

Blum, U., C. Growitsch and N. Krap (2006) "Network Investment and the Threat of Regulation - Preventing Monopoly Exploitation or Infrastructure Construction?" Discussion Paper No. 7, Institut für Wirtschaftsforschung Halle.

Brock, W. and W. Dechert (1985) "Dynamic Ramsey Pricing," International Economic Review, 26: 569-591.

Bruce, R., I. Kessides and L. Kneifel (1999) "Overcoming Obstacles to Liberalization of the Telecom Sector in Estonia, Poland, the Czech Republic, Slovenia, and Hungary," World Bank Technical Paper No. 440, Europe and Central Asia Poverty Reduction and Economic Management Series.

Bruce, R. and R. Macmillan (2002) "Telecommunications in Crisis: Perspectives of the Financial Sector on Regulatory Impediments to Sustainable Investment," International Telecommunications Union, Telecommunications Development Bureau, Document 21.

Brunekreeft, G. (2004) "Regulatory Threat in Vertically Related Markets: The Case of German Electricity," European Journal of Law and Economics, 17: 285-305.

Chiang, A. (1992) Dynamic Optimization. McGraw-Hill, Inc.: New York.

Crooks, N. (2009) "Utilities Defend Rate Hikes Amid Protests - Argentina," Business News Americas, February 10.

Dwivedi, G. and S. Dharmadhikary (2007) "Water: Private, Limited: Issues in Privatisation, Corporatisation and Commercialisation of Water Sector in India," Bandwani (MP), Manthan Adhyayan Kendra.

Ehrhardt, D. and R. Burdon (1999) "Free Entry in Infrastructure," Policy Research Working Paper 2093, World Bank, Washington, D.C.

Engler, M. (2002) "Public Costs, Private Gains: Enron in Guatemala," Report on Guatemala, Fall 2002.

http://www.democracyuprising.com/articles/2002/enron in guatemala.php

Estache, A. and M. Fay (2007) "Current Debate on Infrastructure Policy," Policy Research Working Paper 4410, World Bank, Washington, D.C. 
Fare, R., S. Grosskopf and J. Logan (1985) "The Relative Performance of Private Mixed and State-Owned Enterprises," Journal of Public Economics, 26: 89-106.

Faulhaber, G. and J. Boyd (1989) "Optimal New-Product Pricing in Regulated Industries," Journal of Regulatory Economics, 1: 341-358.

Gaskins, D. (1970) "Dynamic Limit Pricing: Optimal Pricing Under Threat of Entry," Journal of Economic Theory, 3: 306-322.

Gassner, K., A. Popov and N. Pushak (2008) Does Private Sector Participation Improve Performance in Electricity and Water Distribution? PPIAF, World Bank: Washington, D.C.

Glazer, A. and H. McMillan (1992) "Pricing by the Firm Under Regulatory Threat," The Quarterly Journal of Economics, 107: 1089-1099.

Guasch, L. and S. Straub (2006) "Renegotiation of Infrastructure Concessions: An Overview," Annals of Public and Cooperative Economics, 77: 479-493.

Guasch, L., J.-J. Laffont and S. Straub (2003) "Renegotiation of Concession Contracts in Latin America,” Policy Research Working Paper 3011, World Bank, Washington, D.C.

Hamermesh, D. and G. Pfann (1996) "Adjustment Costs in Factor Demand," Journal of Economic Literature, XXXIV: 1264-1292.

Haselip, J. (2004) "The Globalization of Utilities Liberalization: Impacts Upon the Poor in Latin America,” GSGR Working Paper 138/04, The University of Warwick.

Jamaica Public Service Company (2004) "What Has JPS Done to Reduce Electricity Theft?" http://www.jpsco.com/site.nsf/web/electricitytheft.htm

Kamien, M. and N. Schwartz (1991) Dynamic Optimization. Elsevier: Amsterdam.

Kessides, I. (2004) Reforming Infrastructure: Privatization, Regulation and Competition. Oxford University Press: World Bank.

Klevorick, A. (1973) "The Behavior of a Firm Subject to Stochastic Regulatory Review," Bell Journal of Economics and Management Science, 4: 57-83.

Laffont, J.-J. (2005) Regulation and Development. Cambridge University Press: Cambridge, United Kingdom.

Logan, J., R. Masson and R. Reynolds (1989) "Efficient Regulation with Little Information Reality in the Limit?" International Economic Review, 30: 851-861.

Mangasarian, O. (1966) "Sufficient Conditions for the Optimal Control of Nonlinear Systems," SIAM Journal on Control, 4: 139-152. 
Newbery, D. (1999) Privatization, Restructuring and Regulation of Network Utilities. MIT Press: Cambridge, Massachusetts.

Pontryagin, L., V. Boltyanskii, R. Gamkrelidze and E. Mishchenko (1962) The Mathematical Theory of Optimal Processes. Wiley: New York.

Whittington, D., D. Lauria and X. Mu (1991) "A Study of Water Vending and Willingness to Pay for Water in Onitsa Nigeria," World Development, 19: 179-198.

World Bank (2008) Sustainable Infrastructure Action Plan.

\section{$6 \quad$ Appendix}

Lemma 1. If marginal network costs are increasing and $\xi^{\prime \prime}(N) \simeq 0$, then the first-order conditions (5) and (6) are sufficient for maximization iff $2 \quad \gamma^{2}\left[C^{\prime \prime}(N)-2 \xi^{\prime}(N)\right]-1>0$.

Proof. According to the Mangasarian Sufficiency Theorem (Mangasarian, 1966), the necessary conditions of the maximum principle are also sufficient for the global maximization of the objective function $\Pi(0)$ if the Hamiltonian $H$ is concave in $(N, P)$. From (5) and (6), differentiation with respect to $N$ and $P$ yields:

$$
\begin{gathered}
H_{N N}=e^{-r t}\left\{-C^{\prime \prime}(N)-2 \phi \gamma^{2} \xi^{\prime 2}(N)-2 \phi \gamma^{2}[\xi(N)-P] \xi^{\prime \prime}(N)\right\}+\lambda \gamma \xi^{\prime \prime}(N) \\
H_{P P}=e^{-r t}\left(-2 \phi \gamma^{2}\right) \\
H_{P N}=H_{N P}=e^{-r t}\left(1+2 \phi \gamma^{2} \xi^{\prime}(N)\right)
\end{gathered}
$$

Solving for $\lambda$ in (5) and substituting into (28) yields:

$$
\begin{aligned}
& H_{N N}=e^{-r t}\left[-C^{\prime \prime}(N)-2 \phi \gamma^{2} \xi^{\prime 2}(N)+N \xi^{\prime \prime}(N)\right] \\
& \simeq e^{-r t}\left[-C^{\prime \prime}(N)-2 \phi \gamma^{2} \xi^{\prime 2}(N)\right]
\end{aligned}
$$

If marginal network costs are increasing (that is, $C^{\prime \prime}(N)>0$ ), then $H_{N N}<0$. Also, from (29) it is clear that $H_{P P}<0$. Moreover, from (29), (30), and (31) we obtain

$$
H_{N N} H_{P P}-H_{N P}^{2}=e^{-2 r t}\left\{2 \phi \gamma^{2}\left[C^{\prime \prime}(N)-2 \xi^{\prime}(N)\right]-1\right\} \text {. }
$$

Thus, if $2 \phi \gamma^{2}\left[C^{\prime \prime}(N)-2 \xi^{\prime}(N)\right]-1>0$, then the Hessian of $H$ is negative definite $\left(H_{N N}<0, H_{N N} H_{P P}-H_{N P}^{2}>0\right)$, i.e. the Hamiltonian $H$ is concave in $(N, P)$ and the Mangasarian sufficiency conditions are met.

Lemma 2. The steady state is a saddle point equilibrium. 
Proof. Differentiating (5) with respect to $t$ and substituting for $\lambda$ and $\dot{\lambda}$ into (6) lead to the differential equation in $P$

$$
\begin{gathered}
P=-\left(1 / 2 \phi \gamma^{2}\right)\left\{r N+2 \phi \gamma^{2} r[\xi(N)-P]-\gamma[\xi(N)-P]\right. \\
\left.-2 \phi \gamma^{3} \xi^{\prime}(N)[\xi(N)-P]-\gamma P+\gamma C^{\prime}(N)-\gamma \xi^{\prime}(N) N\right\}
\end{gathered}
$$

which along with the differential equation for $N$ in (1) forms a two-equation system. To determine the properties of the steady-state equilibrium we first form the Jacobian matrix of the two-equation system and evaluate it at the steady-state point $E=\left(N^{*}, P^{*}\right)$,

$$
J_{E}=\left[\begin{array}{cc}
\gamma \xi^{\prime}(N) & -\gamma \\
\Omega & r-\gamma \xi^{\prime}(N)
\end{array}\right]_{\left(N^{*}, P^{*}\right)}
$$

where $\Omega=\frac{r+2 \phi \gamma^{2} r \xi^{\prime}(N)-\gamma \xi^{\prime}(N)-2 \phi \gamma^{3} \xi^{\prime \prime}(N)-2 \phi \gamma^{3} \xi^{\prime 2}(N)+\gamma C^{\prime \prime}(N)-\gamma \xi^{\prime \prime}(N) N-\gamma \xi^{\prime}(N)}{\left(-2 \phi \gamma^{2}\right)}$.

The product of the two characteristic roots $v_{1}, v_{2}$ is given by

$$
v_{1} v_{2}=\left|J_{E}\right|=-\left[r+2 \gamma c(1-\rho)^{2}-2 \gamma \xi_{1}\right] / 2 \phi \gamma .
$$

If the Mangasarian sufficiency conditions are met, then $r+2 \gamma c(1-\rho)^{2}-2 \gamma \xi_{1}>0$ which implies that $v_{1} v_{2}<0$ and thus the steady state is locally a saddle point (Chiang, 1992). 